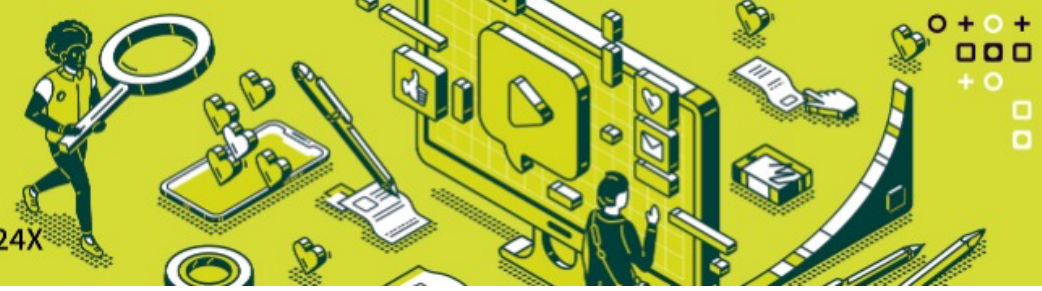

\title{
A IMPORTÂNCIA DA CRIATIVIDADE: UMA RELAÇÃO ENTRE A ESCOLA DE BAUHAUS E A PEDAGOGIA WALDORF.
}

THE IMPORTANCE OF CREATIVITY: A RELATIONSHIP BETWEEN THE BAUHAUS SCHOOL AND WALDORF PEDAGOGY.

PRADO, Felipe Duarte ${ }^{1}$; LAREDO, Gabriel Correa ${ }^{2}$; LAGO NETO, João Caldas do ${ }^{2}$

\author{
${ }^{1}$ Universidade Federal do Amazonas - feduprado@gmail.com \\ ²Universidade Federal do Amazonas - gabrielclaredo@gmail.com \\ 3Universidade Federal do Amazonas - caldas@ufam.edu.br
}

Resumo: A escola de Bauhaus implementou uma metodologia voltada para atividades práticas e artísticas, introduzindo as primeiras ideias do que é conhecido hoje como Design. No mesmo ano, surgiu a pedagogia Waldorf, que se destacou pelo encorajamento da liberdade de pensamento de seus alunos. A principal relação entre essas duas é a preocupação com o desenvolvimento da criatividade. Porém, em Manaus, métodos pedagógicos que priorizam o potencial criativo dos indivíduos se fazem pouco presente no contexto educacional da região. Com o auxílio da aplicação de um formulário para docentes, discentes e egressos do curso de Design da Universidade Federal do Amazonas (UFAM), foi possível obter dados que sustentam o propósito do artigo: expor a falta do uso da criatividade nas instituições de ensino e de que maneira essa subutilização pode afetar negativamente o desenvolvimento das próximas gerações de profissionais, abrindo discussões como o uso do Design como matéria nas escolas, e a falta de preparo para professores.

Palavras-chave: ensino, Bauhaus, Waldorf, criatividade, Design.

\begin{abstract}
The Bauhaus school implemented a methodology focused on practical and artistic activities, introducing the first ideas of what is known today as Design. In the same year, Waldorf pedagogy emerged, which stood out for encouraging students' freedom of thought. The main relationship between these two is the concern with the development of creativity. However, in Manaus, pedagogical methods that prioritize the creative potential of individuals are little present in the educational context of the region. With the help of applying a form for teachers, students and graduates of the Design course at the Federal University of Amazonas (UFAM), it was possible to obtain data that support the purpose of the article: exposing the lack of use of creativity in educational institutions and how this underutilization can negatively affect the development of the next generations of professionals, opening discussions such as the use of Design as a subject in schools, and the lack of preparation for teachers.
\end{abstract}

Keywords: teaching, Bauhaus, Waldorf, creativity, Design.

\footnotetext{
${ }^{1}$ Graduando em Design e bolsista de iniciação científica pelo projeto SUPER/UFAM - 2020.

2 Programa de Pós-Graduação em Design, Universidade Federal do Amazonas.
} 


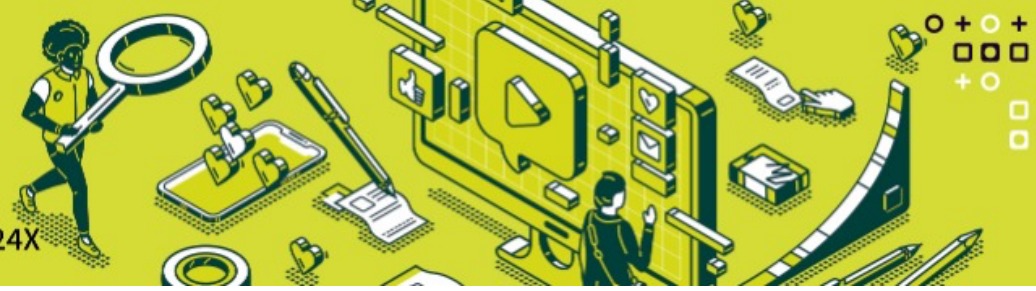

\section{INTRODUÇÃO:}

O Design surgiu a partir de uma nova abordagem metodológica de ensino, que unificou arquitetura, arte, função e indústria, influenciando a educação utilizando a criatividade dos seus alunos. Essa escola se chamava Bauhaus, fundada em 1919 na Alemanha, ficou conhecida por esse método revolucionário, que tinha como premissa a inclinação para a arte e o artesanato, porém, treinando seus alunos em todos os ramos do design, por conta dessa nova ideia "dissidente", a instituição acabou sendo extinta pelo nazismo (GAMBARATO, 2010). Nesse mesmo período, também na Alemanha, surgiu a pedagogia Waldorf, que consiste em uma forma de ensino empirista, onde as crianças têm acesso a muito mais aulas práticas que o ensino tradicional, aprendendo por experimentação, desenvolvendo seu potencial criativo através de diversas atividades (ALVARES, 2010).

Segundo Lima (2018) e Alvares (2010), na Waldorf é utilizado a arte e suas linguagens como metodologia de ensino, onde essa pedagogia tem como princípio encorajar a liberdade de pensamento e a criatividade de seus alunos. Lira (2018) enfatiza a relação dessa pedagogia com a escola de Bauhaus, e com o Design. Apesar de ambas formas de ensino terem feito um século de idade em 2019, no Brasil, como disse Braga (2019), o cidadão comum não entende completamente o design, por ser amplo, e a pedagogia Waldorf é minoria nas regiões, e em Manaus, inexistente (Federação das Escolas Waldorf no Brasil, 2021).

Segundo Teixeira (2019), a criatividade é um dos predicados com o qual o designer tem o poder de se destacar, apesar da grande quantidade de profissionais, poucos buscam pelo desenvolvimento dela. É visível a importância do potencial criativo para o mercado de trabalho, então, precisa-se de novas estratégias pedagógicas para abordar essa necessidade (OLIVEIRA e ALENCAR, 2010). Este artigo tem como objetivo descrever a importância da criatividade, demonstrando como se relacionam: a pedagogia Waldorf, a escola de Bauhaus e o curso de Design da Faculdade de Tecnologia na Universidade Federal do Amazonas, destacando como a falta de metodologias de desenvolvimento criativo podem afetar a educação no município de Manaus. Por meio de um levantamento de dados feito através de um formulário quanti-qualitativo, busca-se entender o motivo da subutilização da criatividade, que é tão importante para o mercado de trabalho.

\section{REVISÃO BIBLIOGRÁFICA NARRATIVA:}

Lourenço e Ribeiro (2006) afirmam que a escola de Bauhaus foi importante para a pedagogia, a arte, artesanato e arquitetura, mas também foi o berço do design, e por ser pioneira ao ensiná-lo, unindo arte, técnica e função, deu forma ao que se conhece como Design, onde os alunos desenvolviam a capacidade de observação e tinham contato com diversos materiais. Lima (2018) diz que a pedagogia Waldorf, também possui essa preocupação da função do ensino com sentido artístico, e suas relações com outras disciplinas, onde nela, são feitos exercícios práticos a partir do desenho, utilização das cores e aulas de artes, estimulando a criatividade. A principal relação dos dois é o foco no desenvolvimento criativo, aplicando um método de ensino prático, resolvendo problemas e estimulando seus alunos (LIRA, 2018).

Segundo Braun, Fialho e Gomez (2014), a educação sempre foi um tema discutido no mundo no que diz respeito a sua importância para o crescimento em esferas intelectuais, econômicos e sociais, e também, para o indivíduo e para o coletivo. O início do desenvolvimento criativo, do seu uso e aprimoramento, ocorre principalmente no contexto escolar, onde o foco é o aluno, estendendo-se ao 


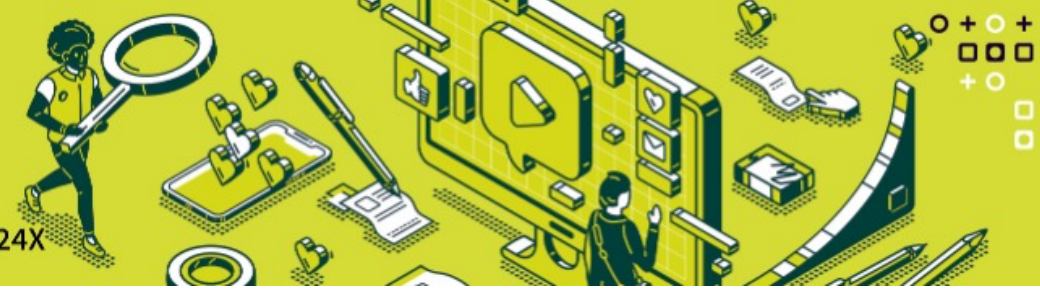

meio social. Onde ele é preparado para a resolução de problemas e a construção de novas respostas. Sendo assim, escolas que não possuem preocupação com a criatividade, possuem maior quantidade de evasão (SILVA e AMOROSO, 2016), sendo necessária uma reformulação das concepções de ensino e aprendizagem, para que as organizações possam acompanhar a mudança do mercado de trabalho, proporcionando assim, um espaço de mudança e divulgação do saber, gerando um desenvolvimento de novas aptidões (BRAUN, FIALHO e GOMEZ, 2014).

Oliveira e Alencar (2010) enfatizam que quando não há um preparo, a criatividade dos alunos acaba sendo sufocada, pois os cursos de formação pedagógica não oferecem esse tipo de preparação. No ensino, a criatividade tem uma grande influência, principalmente quando se inserem atividades desafiadoras que permitam a criação de modos diferenciados de resoluções de problemas corriqueiros. Então, com o uso de metodologias criativas dentro do contexto educacional, pode-se oferecer ao aluno e aos docentes uma base sólida para lidar com situações que aparecerem no dia a dia, resolvendo problemas (SILVA e AMOROSO, 2016).

\subsection{A Escola de BauHAus:}

Staatliches Bauhaus foi uma escola de arquitetura, design e artes aplicadas primeiramente fundada em Weimar, na Alemanha, pelo arquiteto Walter Gropius em 1919. Ela teve origem da união da Academia de Belas Artes e da Escola de Artes e Ofícios. Seu nome é uma derivação da palavra alemã Hausbau, que significa "construção de uma casa", com a ordem invertida, sendo assim Bauhaus a "casa de construção". A instituição oferecia o ensino de diversos ofícios vistos por Gropius como aliados da arquitetura, considerada pelo mesmo como a matriz das artes (BRITANNICA, 2020).

No ano de 1925 a escola de Bauhaus foi transferida para a cidade de Dessau, instalada num edifício de arquitetura industrial moderna, projetado por Walter Gropius. Com a construção desse edifício, Gropius introduziu características estruturais que no futuro se tornariam símbolos da arquitetura modernista, como uma estrutura de aço, uma parede de cortina de vidro assim como um plano assimétrico em formato de cata-vento (LENINE, 2016). Em 1928, Gropius renunciou ao cargo de diretor devido às contínuas críticas direcionada ao mesmo e ao trabalho desenvolvido na instituição. Em seu lugar assumiu o arquiteto suíço Hannes Meyer, que tinha maior apreço à padronização e ao processo de produção, assim diminuindo a ênfase na arte e no produto em si, o que levou a escola à um caminho de racionalismo e técnico (BASSO e STAUDT, 2010). A escola teve suas atividades encerradas oficialmente após uma frustrada tentativa de se recompor em 1933, quando a escola teve sua última cede em Berlim fechada pelo regime nazista (LENINE, 2016). Devido às diversas mudanças de diretor e foco da instituição não se pode afirmar que existiu uma pedagogia de ensino concreta e constante, mas apesar da escola ter se direcionado ao desenvolvimento voltado para a indústria o desejo inicial de Gropius de capacitar profissionais que administrassem o conhecimento técnico-prático com o artístico-teórico simultaneamente se fez presente em todos os projetos criados na mesma (BONI, PIRES, SADER E LANDIM, 2018).

$\mathrm{O}$ intuito da Bauhaus era buscar o artista perfeito, que não se prendesse somente a arte, mas sim as técnicas práticas simultaneamente. Ao longo dos anos que a escola funcionou, ambas habilidades foram praticadas, o que talvez seja um indicativo de que havia preocupação com o uso do conhecimento de forma criativa, através da prática (BONI, PIRES, SADER e LANDIM, 2018). Na instituição, acreditava-se no aprender fazendo (learning by doing) e as realizações eram baseadas na técnica e no idealismo, destacou Basso e Staudt (2010). Esse "aprender fazendo" era, enquanto 


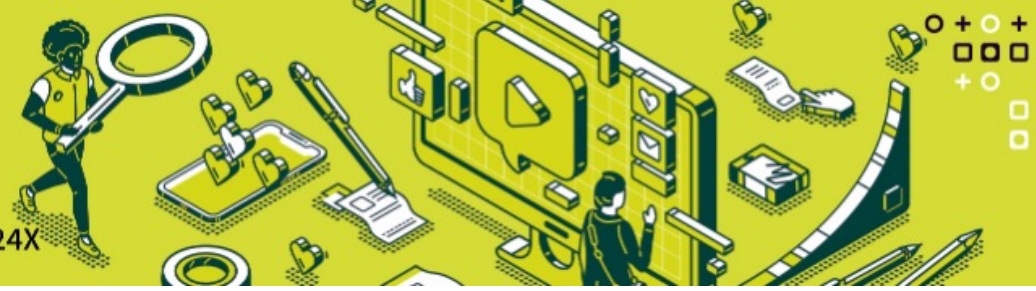

disciplina, o ofício manual, o que acabou se transformando na precursora da metodologia de ensino da Bauhaus. O curso foi destinado a libertar o potencial criativo dos alunos, dando-lhes compreensão dos materiais da natureza, e demonstrando os princípios básicos da atividade criativa nas artes visuais (GAMBARATO, 2010).

O uso da criatividade era diretamente influenciado pela imposição hierárquica: mestre, oficial e aprendiz, demonstrando um empecilho para o desenvolvimento individual artístico, pois a avaliação dos trabalhos era ligada a preferência dos professores. Porém, não é correto dizer que essas limitações impediram o avanço criativo dos alunos, pois entende-se que a prática foi uma maneira de estimulalos. Ainda que a Bauhaus fizesse uso deliberado da prática e do ensino experimental, não adotava uma pedagogia construtivista. Entretanto pode-se dizer que utilizavam de uma junção de uma abordagem racional e analítica a fim de explorar as possibilidades artísticas e conceituais, assim estimulando a criatividade de seus alunos ainda que seguissem determinado padrão (BONI, PIRES, SADER e LANDIM, 2018).

\subsection{A PEDAGOGIA WALDORF E SUA METOdOLOGIA:}

As escolas Waldorf são instituições educacionais que fogem do ensino tradicional. Possuem notoriedade e tradição desde seu surgimento, por ser uma forma de ensino alternativa, diferente das comuns, abordadas em países ocidentais, o que fez esse método ser muito prestigiado em todo o mundo. A filosofia educacional da Waldorf tem por missão desenvolver, não só o lado intelectual, mas também o emocional, o psicológico, o intuitivo e a experiência concreta, sendo esses tópicos considerados tão importantes quanto o ensino das matérias que alimentam a capacidade intelectual e social da criança. Para conseguir tal feito, nas escolas é introduzido na vida diária do indivíduo a fabricação de objetos, através das artes manuais, entre elas: artesanato, escultura, marcenaria, entre outros (ALVARES, 2010).

Segundo Cichocki (2016), a Pedagogia Waldorf surgiu de um impulso social, em uma época que a Alemanha estava passando por um momento difícil, após a primeira guerra. Rudolf Steiner, criador da Antroposofia, foi convidado para organizar uma escola que fosse capaz de desenvolver seres humanos melhores para a sociedade. Assim, deu início a primeira escola Waldorf, na Alemanha, em 1919. Essa não é uma escola religiosa, onde se ensina Antroposofia. O que ocorre é a observação, por parte dos professores, do ser humano e da imagem que essa filosofia faz do mesmo. Trata-se de uma aplicação de processos artísticos para que o desenvolvimento mental ocorra numa dimensão de equilíbrio entre razão e sensibilidade (ROMANELLI, 2008).

Essa pedagogia iniciou no Brasil em 1956 por imigrantes alemães, que fundaram a primeira Escola Waldorf Rudolf Steiner na cidade de São Paulo. A maioria delas é de ensino particular ou possui associações que as financiam. Apenas na Bahia e em Minas Gerais que existem escolas Waldorf públicas. Na região Norte não possui nenhuma delas (PEREIRA,2017).

Romanolli (2008) esclarece que, para Steiner, o querer é desenvolvido no primeiro setênio, o sentir durante o segundo e o pensar ao longo do terceiro. Segundo as crianças aprendem o convívio com outras em diferentes idades, onde amadurecendo juntas, as pequenas aprendem a plantar, cuidar, do que plantaram, colher, armazenar e, por fim, fazer os próprios lanches ou refeições. Tudo com orientação de professores (PEREIRA, 2017). E, como disse Lira (2018), não é uma escola para acúmulo de conteúdo, mas sim de busca criativa para os problemas apresentados. Pereira (2017) destaca, também, que as matérias artísticas são parte fundamental no currículo da Pedagogia Waldorf, onde o 


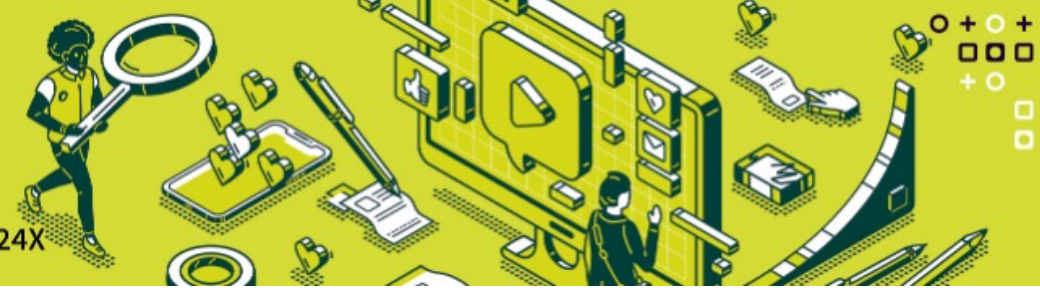

indivíduo aprende, tricô, música, mexer com argila, tudo para que a criatividade seja desenvolvida. Há ainda teatros ensaiados, escolhidos e desenvolvidos pelos adolescentes que constroem o cenário, figurinos.

As crianças participam ativamente de todo o processo. O desenvolvimento delas é integral, assim, há atividades propostas semanalmente, como também aquelas que são desenvolvidas diariamente. $\mathrm{A}$ pedagogia Waldorf, acredita que, a criança dessa faixa etária, desenvolve suas capacidades de contato com o ser humano, por isso, a importância do exemplo, consequentemente, o professor deve ser digno de ser imitado (CICHOCKI, 2016). Outra característica marcante da pedagogia Waldorf, é o fato de o professor atuar durante 8 anos consecutivos com uma mesma turma, o que possibilita uma melhor ligação entre o aluno e o docente (PEREIRA, 2017).

O segundo setênio é o da juventude, de sete aos 14 anos, onde há o desenvolvimento emocional e o seu cérebro já se encontra mais evoluído, facilitando a absorção de conteúdo, e logo, estimulando o aprendizado e não a "decoreba". Ou seja, é nesse período que o psicológico do indivíduo é tido como foco, promovendo o amadurecimento. $O$ docente deve ser a autoridade amorosa nesse ciclo, ser alguém a quem o aluno tenha admiração (PEREIRA, 2017). Segundo Cichocki (2016), as escolas Waldorf consideram o ensino como gradual, pois as crianças passam por fases de desenvolvimento, que devem ser respeitadas. O mundo, para elas, deve ser apresentado calmamente, para que assim a criança vá se apropriando com naturalidade. Romanolli (2008) completa que a importância que Steiner dedicou à formação do ser humano, através de sua pedagogia, é visível. Também é possível entender porque essa metodologia caminha a passos lentos, afinal, precisa-se de instrução para educar a vontade latente na criança. E para que se tenha uma mudança na educação brasileira, só é possível oferecendo cursos para os professores, incentivando-os a entender o funcionamento dessa pedagogia (PEREIRA, 2017).

\subsection{A CRIATIVIDADE:}

Atualmente, a educação busca métodos e estratégias de ensino visando à formação do indivíduo nas diversas áreas do conhecimento, desenvolvendo: a afetividade, cognição e a relação social. Onde se compreende o uso do poder criativo, sendo ele um recurso essencial para a promoção do conhecimento (SILVA e AMOROSO, 2016). A criatividade está presente em diversos segmentos da vida humana, principalmente no campo do trabalho e da educação, constituindo-se em um recurso essencial para que o indivíduo possa lidar com conflitos, tensões e exigências do mundo contemporâneo (OLIVEIRA e ALENCAR, 2010).

Segundo Almeida e Alencar (2010), a criatividade é um fenômeno complexo e diversificado, que se manifesta em diferentes fases e nos campos da atividade humana. Pinho e Souza (2014) abordam que: "A criatividade em sua ação original de pensar, refletir, livre, flexível, nova e consciente a partir de sua realidade de forma interligada com o processo inovador; busca organizar este criar com certo êxito no que se refere às práticas inovadoras em promover mudanças de um ensino transmissivo do saber para a produção do conhecimento que possibilita tanto o docente quanto o discente em serem protagonistas de sua própria aprendizagem". Devido ao desenvolvimento tecnológico, científico, industrial, e outras áreas, tem-se problemas ambientais, de saúde, de desorganização social, e o mundo atual requer criatividade na busca de soluções (FREIRE, 2010). Por consequência desse cenário de constates mudanças, o mercado de trabalho exige profissionais capacitados de prever e identificar problemas, além de estarem aptos a propor soluções. Por consequência, as empresas se preocupam 


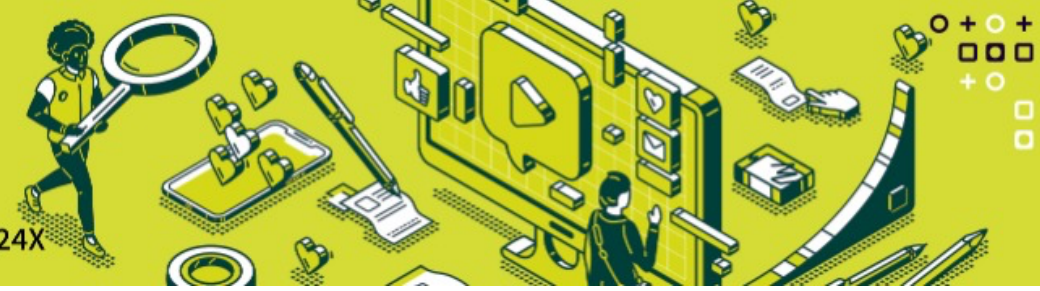

onde $Z$ é o valor crítico na distribuição normal padronizada para o nível de confiança $\alpha$ desejado; $p$ proporção na amostra e $n$ o tamanho da amostra.

\section{ANÁlISE dOS RESUltados}

A aplicação de um formulário semiestruturado, formado por 3 segmentos, foi essencial para que se tornasse possível a análise das necessidades da área educacional em Manaus. Tendo como base a opinião de egressos, docentes e discentes, foram feitas perguntas gerais, que visam coletar dados comuns e contextualizar os participantes, e específicas, designadas aos mesmos, de acordo com grupo a que pertencem. As informações foram coletadas no período de 01 a 31 de janeiro de 2021 mediante aplicação de um questionário quanti-qualitativo online.

Admitindo o desconhecimento do percentual histórico de usuários com experiência nas pedagogias de Waldorf e Bauhaus no ensino do Design. Esta situação é representada utilizando na equação (1) os seguintes parâmetros: a proporção na amostra $p=0,50$, o valor critico $Z=1,96$, e erro de amostragem $d$, determina-se o tamanho, $n$, da amostra necessária para cada segmento descrito.

Tabela 1 - Tamanho da amostra segundo o erro de amostragem e valor critico $Z=1,96$.

\begin{tabular}{|l|l|l|l|}
\hline & \multicolumn{3}{|c|}{ Segmentos } \\
\hline Amostra & Docente & Egressos & Discentes \\
\hline População $N$ & 30 & 300 & 200 \\
\hline Amostra $n$ & 14 & 10 & 68 \\
\hline Erro de amostragem & 0,20 & 0,30 & 0,10 \\
\hline
\end{tabular}

Neste estudo, o tamanho da amostra implementado foi 14 docentes do Departamento de Design da Faculdade de Tecnologia da UFAM, 10 egressos do curso de Design e 68 discentes com o respectivo erro de amostragem descrito por segmento na Tabela 1 . Os dados referentes a essa amostra foram coletados por meio do questionário eletrônico disponibilizado no endereço https://forms.gle/GzmSCdbyWbvAmPJX6.

\subsection{ANÁLISE DO QUESTIONÁRIO GERAL}

A resposta unânime da primeira pergunta foi tida como sendo a mais importante para o levantamento de dados, pois ela justifica o argumento principal do artigo. Todos os participantes concordaram que o estímulo da criatividade é importante para o ensino, totalizando 92 respostas. Foi possível identificar, Figura 1, que $84,80 \%$ dos entrevistados afirmam desconhecer instituições que utilizam esta metodologia de ensino, evidenciando a carência de um ensino com uma abordagem mais criativa em Manaus, favorecendo a subutilização da criatividade nas escolas da região. E, mesmo nas respostas positivas, $15,20 \%$, poucas instituições foram citadas. 


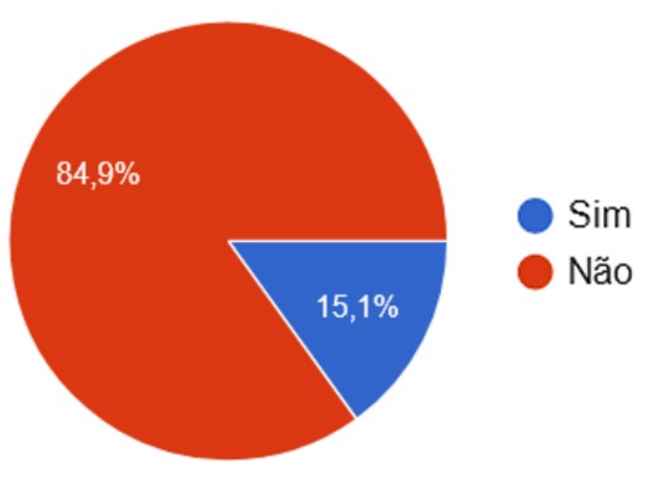

Figura 1 - Você conhece Instituições que utilizam de uma abordagem de ensino mais criativa em Manaus?

A Figura 2 demonstrou que, para $79,6 \%$ dos participantes, os métodos de ensino em Manaus são medianos, se acumulando nas respostas 2 e 3, e pouco efetivos, indicando que a falta de abordagens metodológicas diferentes faz com que algumas pessoas sintam dificuldades de aprendizado. Sustentando, então, a pauta principal do artigo de que a criatividade é necessária no ensino.

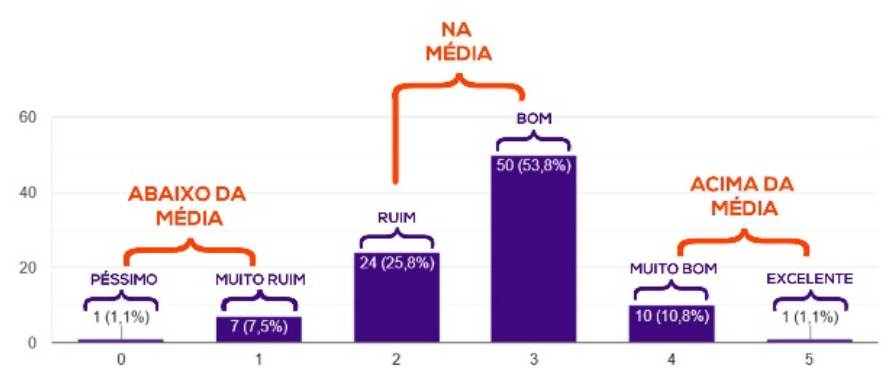

Figura 2- Em uma escala de 0 a 5, o quão efetivo você acha que são os métodos de ensino em Manaus?

\subsection{ANÁLISE DO QUESTIONÁRIO DOS EGRESSOS}

As informações do questionário para os egressos serviram para ampliar a visão quanto a importância da criatividade e seu impacto dentro e fora do curso de graduação em Design da Universidade Federal do Amazonas, assim como a influência na vida profissional. Ao todo foram feitas 6 perguntas específicas para este grupo. A Figura 3 evidencia o problema crônico de estimulo da criatividade no ensino fundamental e ensino médio. 

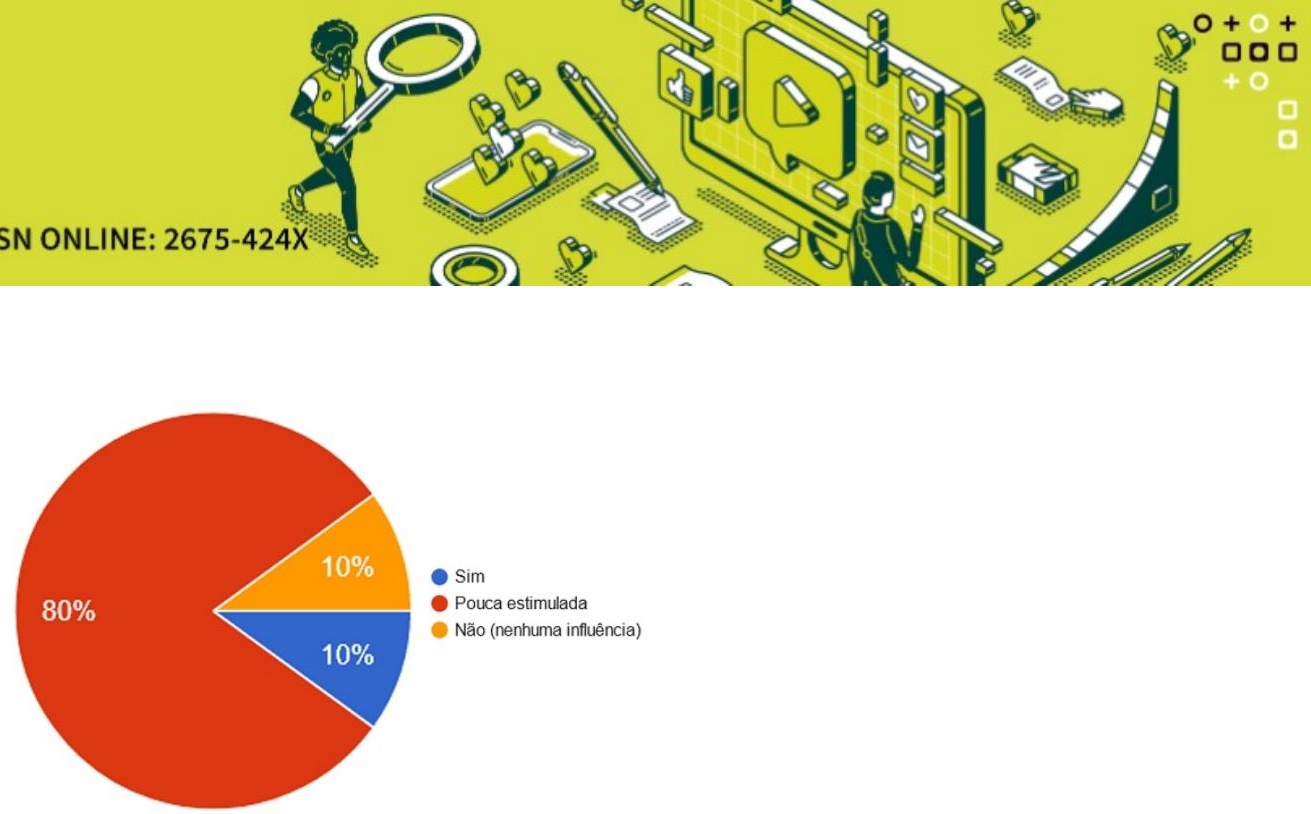

Figura 3 - A sua criatividade foi estimulada no seu período escolar (fundamental I e II, ensino médio)?

A falta do estímulo da criatividade ao longo do período escolar coloca os discentes em formação em desvantagem, tendo em vista que a rotina profissional de um designer exige extremamente de seu potencial criativo, como afirmado pelos resultados obtidos na Figura 4.

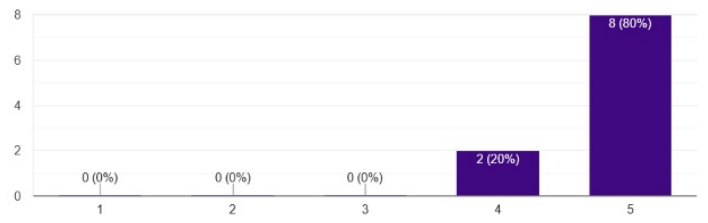

Figura 4 - De 0 a 5, o quanto a criatividade se faz presente no seu trabalho?

\subsection{ANÁLISE DO QUESTIONÁRIO DOS DOCENTES}

Levando em consideração que existem diversas metodologias, foi importante obter a opinião os docentes do curso de Design da Universidade Federal do Amazonas, uma vez que trabalham diretamente com o ensino e podem contribuir na melhor percepção em relação a criatividade. Ao todo foram feitas 8 perguntas. A Figura 5 mostra a preocupação dos professores participantes em agregar o estímulo da criatividade em seus métodos de ensino, e a clara percepção que a criatividade pode ser ensinada ao longo da formação do discente.

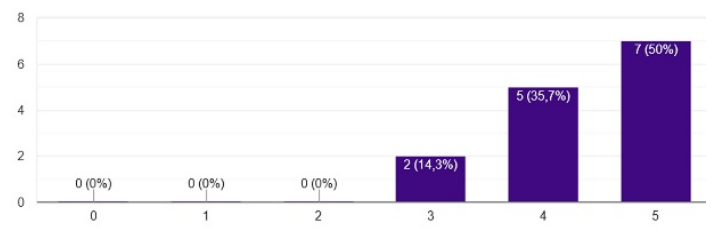

Figura 5 - Em uma escala de 0 a 5, quanto você estimula a criatividade nos seus alunos?

\subsection{ANÁLISE DO QUESTIONÁRIO DOS DISCENTES}

A opinião dos alunos serviu para identificar as necessidades recentes, permitindo a compreensão de que maneira a aplicação de certas metodologias pode influenciar no aprendizado, especificamente no 


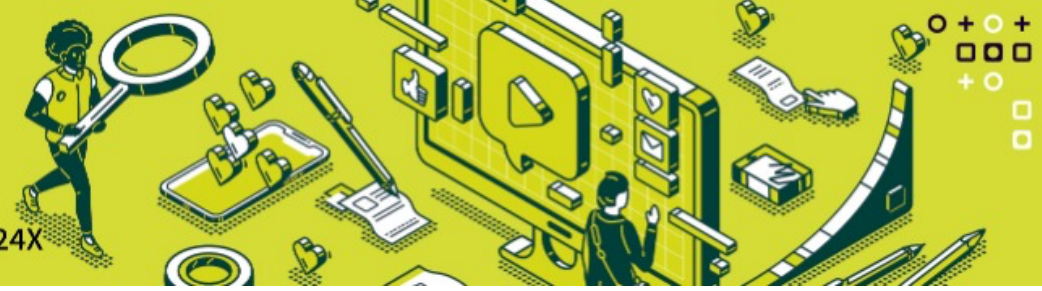

curso de Design da UFAM. Ao todo 7 perguntas foram elaboradas. O "método Bauhaus" e a pedagogia Waldorf priorizam a utilização de atividades práticas para estimular as habilidades criativas, porém, não deixando de lado as aulas puramente teóricas. E, conforme apresentado na Figura $6,89,70 \%$ dos discentes entrevistados acreditam que atividades práticas sejam mais efetivas que atividades teóricas.

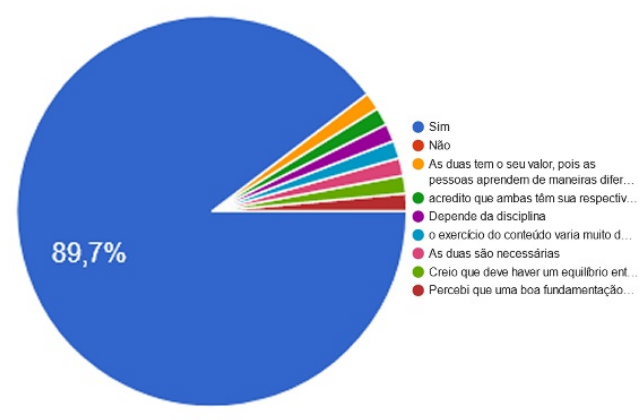

Figura 6 - Você acredita que atividades práticas são mais efetivas que atividades puramente teóricas?

Apesar de $14,7 \%$ dos discentes não acreditarem que a criatividade possa ser ensinada, a maioria dos participantes acredita que sim, reafirmando a opinião geral dos professores, que consideram verdadeira essa possibilidade. A Figura 7 reforça os resultados dessa preocupação com o desenvolvimento criativo.

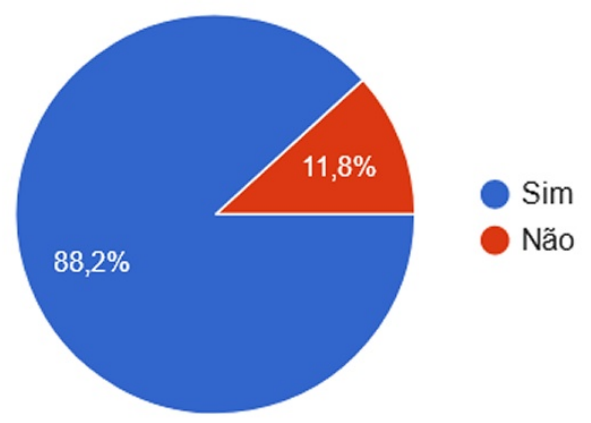

Figura 7 - Você sente que a sua criatividade é estimulada no curso de Design?

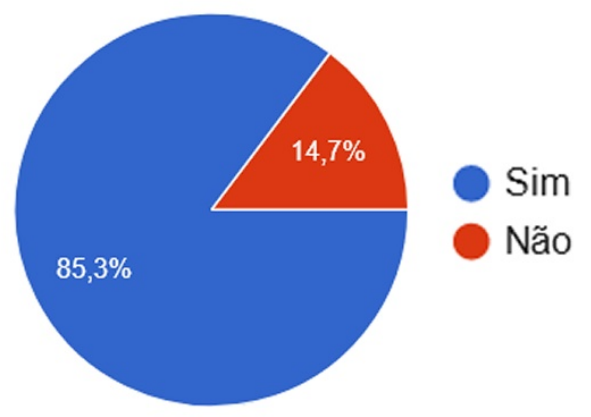

Figura 8 - Você acha que a criatividade pode ser ENSINADA? 


\subsection{REFLEXÕES}

Relacionando as respostas obtidas de cada segmento discente, docente e egresso foi possível tirar conclusões sobre a principal pauta do artigo (a importância da criatividade). Tais reflexões tiveram como base dados comparativos retirados do próprio questionário, e serviram para identificar problemas que são comuns nos três segmentos pesquisados. Na Figura 9, 10 e 11, a mesma pergunta foi realizada aos três grupos tendo como resposta a ausência de preocupação com o desenvolvimento da criatividade no período escolar. Isso demonstra que a subutilização de práticas criativas dentro das instituições de ensino em Manaus é um problema recorrente.

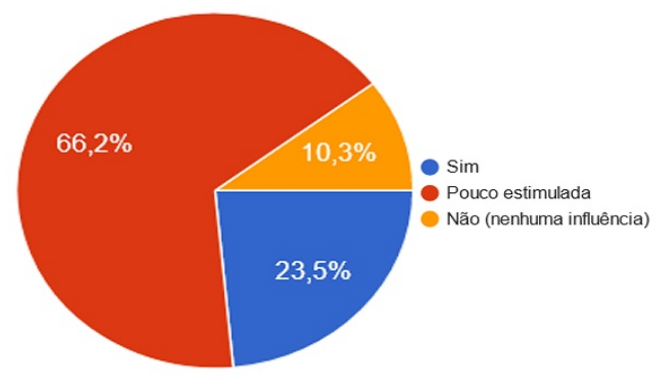

Figura 9-A sua criatividade foi estimulada no seu período escolar (fundamental I e II, ensino médio)?

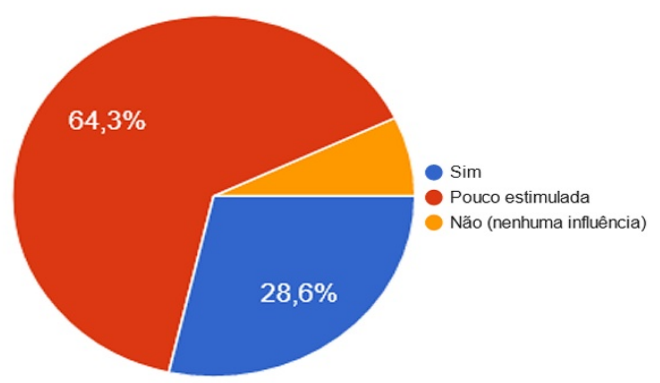

Figura 10 - A sua criatividade foi estimulada no seu período escolar (fundamental I e II, ensino médio)?

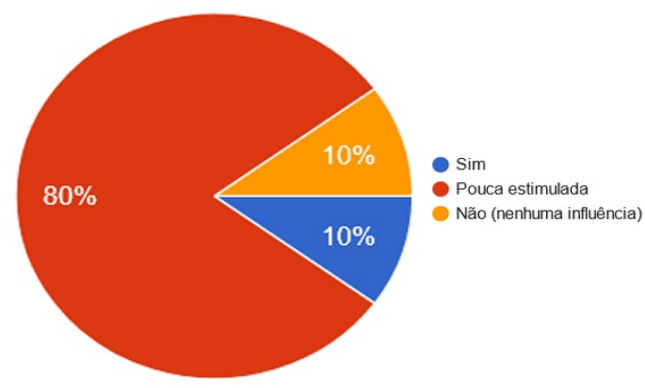

Figura 11 - Egressos A sua criatividade foi estimulada no seu período escolar (fundamental I e II, ensino médio)?

Na Figura 12, observa-se que $97,1 \%$ dos discentes afirma sentir a necessidade de mudanças, o que valida a opinião de que as metodologias tradicionais tipicamente empregadas nas instituições da região podem estar ultrapassadas, ainda que possam ser efetivas em certo nível. 

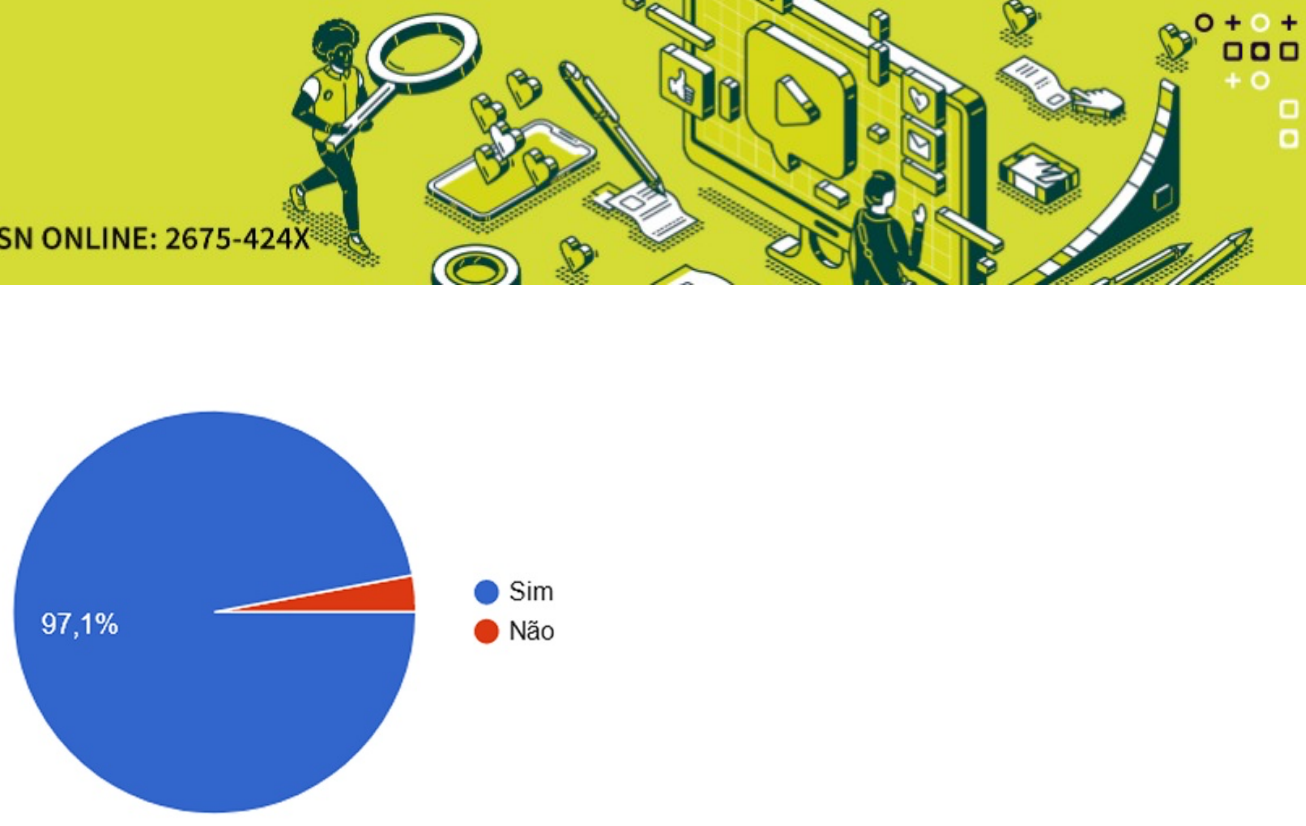

Figura 12 - Você sente/sentiu a necessidade de metodologias de ensino diferentes em Manaus?

Um dos tópicos a ser levantado nesse artigo é a importância do Design para o ensino escolar. Relacionando os problemas encontrados nos três grupos estudados, pode-se observar que o meio escolar em Manaus ainda não superou os meios tradicionais de ensino. Isso significa que a criatividade ser deixada de lado não é algo novo.

\section{CONCLUSÕES}

Diante das análises bibliográficas narrativas, podemos concluir que a criatividade ainda não é vista como prioridade por grande parte das instituições de ensino em Manaus, que se mantém presas aos métodos de ensino tradicionais, não buscando novas metodologias pedagógicas. A região norte ainda se apresenta muito decadente quando o assunto é desenvolvimento do potencial criativo, por oferecer poucas opções. Um grande exemplo disso é a inexistência das escolas Waldorf, que foram citadas no artigo e são referência mundialmente no quesito.

Dos métodos de educação abordados podemos dar destaque para os utilizados pela escola de Bauhaus, que além de inovar e aplicar a criatividade como principal pauta, teve impacto direto na economia do país (Alemanha), pois trouxe à tona o potencial de criação de diversos indivíduos, atraindo o interesse e investimento de outros países devido a sua grande capacidade criativa. Tendo em vista, que a humanidade é fruto da constante evolução de tecnologias, os reflexos dessa negligência com a criatividade podem ir além do indivíduo, tendo influência no desenvolvimento da região e podendo afetar até mesmo gerações.

As escolas públicas passam por um descaso muito grande por parte do Governo, o que faz com que os alunos não tenham vontade de aprender e que não tenham acesso a um ensino de qualidade. Mesmo para os pais que possuem condições de pagar uma educação particular para seu filho, não existe uma diversidade nos métodos pedagógicos da região. Isso abre a discussão para a aplicação da matéria de Design nas escolas, assim, podendo trazer para os alunos a busca pela resolução de problemas, desenvolvimento da criatividade, podendo também despertar o interesse pelo aprendizado.

Com os resultados obtidos tanto nas pesquisas realizadas quanto no formulário aplicado, fica claro que a maioria dos indivíduos ingressa no curso de Design sem bases prévias de conhecimento criativo, o que os bota em extrema desvantagem ao se desenvolverem como profissionais dificultando entendimentos e atrasando muitas etapas. Pelo fato de a área ainda ser muito nova no Brasil, a demanda de profissionais capacitados é crescente e a habilidade de criar se torna essencial, uma vez que é preciso saber prever e lidar com problemas. 


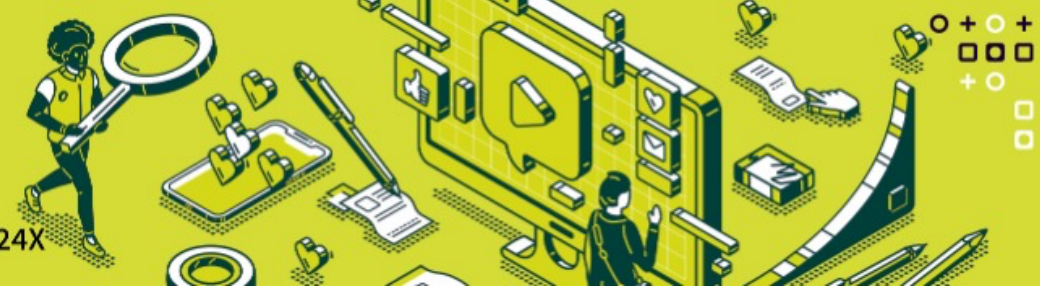

Outro ponto que colabora para a falta de exploração da criatividade no meio escolar é a falta de professores qualificados, que não têm oportunidade de se especializar nessa área, pela inexistência de devida formação. As instituições pedagógicas não ensinam metodologias voltadas para a criatividade, o que torna a possibilidade de ela ser posta em prática quase nula. Apesar da importância do potencial criativo ser reconhecida no âmbito escolar, são quase inexistentes instituições que tenham matérias voltadas para isso em suas grades curriculares.

Conclui-se que o sistema educacional atual necessita de reformas, tanto nos cursos ofertados quanto nas metodologias de ensino oferecidas visando desenvolver o potencial de criação das gerações que estão por vir, capacitando-os para o mercado de trabalho, e para as exigências do mundo contemporâneo.

\section{REFERÊNCIAS}

ALMEIDA, J. M. O.; ALENCAR, E. M. L. S. Criatividade no Ensino Médio segundo seus estudantes. Paidéia (Ribeirão Preto), Ribeirão Preto, v. 20, n. 47, p. 325-334, dez. 2010. Disponível em: http://www.scielo.br/scielo.php?script=sci_arttext\&pid=S0103863X2010000300005\&lng=en\&nrm=is o>. Acesso em: 4 jan. 2021.

ALVARES, S. L. Traduzindo em formas a pedagogia Waldorf. Campinas, Unicamp, 2010.

BASSO, C. R.; STAUDT, D. A Influência da Escola de Ulm e Bauhaus na estrutura curricular das escolas. Revista Conhecimento Online, Novo Hamburgo, v. 2, p. 18-31, set. 2010. ISSN 2176-8501. Disponível em:

https://periodicos.feevale.br/seer/index.php/revistaconhecimentoonline/article/view/144. Acesso em: 28 Dez. 2020.

BONI, C.; PIRES, M. P.; SADER, A. P. C.; LANDIN, P. C. Reflexões sobre o uso da razão e da criatividade no atual ensino do design na Europa e nos tempos da Bauhaus. Projética. Londrina, v. 10, n. 2 p. 8192, 2019.

BRAGA, M. C. Os desafios para o designer no mercado de trabalho. Disponível em:

https://www.ufrgs.br/jornal/os-desafios-para-o-designer-no-mercado-de-trabalho/ Acesso: 10 dez. 2020.

BRAUN, J. R. R.; FIALHO, F. P. A.; GOMEZ, L. S. R. Aplicações da criatividade na educação brasileira. PUC-PR, Curitiba, v. 17, n. 52, p. 575-593, abril de 2017.

BRITANNICA, The Editors of Encyclopaedia. Bauhaus. www.britannica.com/topic/Bauhaus. Acesso em: 2 jan. 2021.

BONI, C.; PIRES, M. P.; SADER, A. P. C.; LANDIN, P. C. Reflexões sobre o uso da razão e da criatividade no atual ensino do design na Europa e nos tempos da Bauhaus. Projética. Londrina, v. 10, n. 2 p. 81 92, 2019.

CAMPOS, E. Afinal, o que foi a Bauhaus e que legados ela deixou no Design contemporâneo? Disponível em: https://medium.com/cesar-update/afinal-o-que-foi-a-bauhaus-e-que-legados-eladeixou-no-design-contemporâneo-e0d91c0b11e2. Acesso em: 5 jan. 2021.

CICHOCKI, M. S. É Tempo de Brincar: Pedagogia Waldorf. In: Congresso Nacional de Educação, 13a Edição, 2017, Curitiba.

GAMBARATO, R. R. Ícones do design: da Bauhaus ao produto final. Revistas USP, São Paulo, v. 6, n. 1, P. 18-25, junho de 2010.

LENINE. Bauhaus, 1919-1933. Disponível em: https://lenineon.medium.com/bauhaus-1919-1933bb36c1101f65. Acesso em: 5 jan. 2021. 
LIMA, C. B. Pedagogia Waldorf: A arte como mediação no processo de ensino-aprendizagem. Disponível em: https://editorarealize.com.br/artigo/visualizar/48526. Acesso em: 15 dez. 2020.

LIRA, A. O Design e a Pedagogia Waldorf. Disponível em:

http://www.adegraf.org.br/artigo/2018/12/o-design-e-a-pedagogia-waldorf. Acesso: 28 nov. 2020.

LOURENÇO, C. A.; RIBEIRO, S. M. História e Pedagogia: a influência da Bauhaus para o Ensino do Design. Disponível em:

https://fido.palermo.edu/servicios_dyc/publicacionesdc/vista/detalle_articulo.php?id_articulo=5504 \&id_libro=11. Acesso em: 25 nov. 2020.

OLIVEIRA, Z. M. Fatores influentes no desenvolvimento do potencial criativo. Estud. psicol.

(Campinas), Campinas, v. 27, n. 1, p. 83-92, Mar. 2010.

www.scielo.br/scielo.php?script=sci_arttext\&pid=S0103-166X2010000100010\&lng=en\&nrm=iso >. Acesso em: 3 jan. 2021.

OLIVEIRA, E. L.; ALENCAR, E. M. Criatividade e escola: limites e possibilidades segundo gestores e orientadores educacionais. Scielo, Campinas, v. 14, n. 2, julho de 2010.

PEREIRA, M. C. R. A Proposta da Pedagogia Waldorf na Iniciativa Pública: Um estudo de caso. Disponível em: https://monografias.brasilescola.uol.com.br/pedagogia/a-proposta-da-pedagogiawaldorf-na-iniciativa-publica-estudo-de-caso.htm\#indice_2. Acesso em: 23 Dez. 2020.

PINHO, M. J.; SOUZA, K. P. Escola Contemporânea Criativa e Inovadora na transição de paradigmas. SINOP, Mato Grosso, v. 5, n. 4, 2014.

ROMANELLI, R. A. Pedagogia Waldorf: Um Breve Histórico. Revista da Faculdade de Educação. Mato Grosso, v. 10, n. 6, 2008.

SÃO PAULO, Federação das Escolas Waldorf no Brasil. Mapa de escolas Waldorf no Brasil. Disponível em: http://www.fewb.org.br/mapa.html. Acesso: 25 nov. 2020.

SILVA, D. M.; AMOROSO, S. R. B. A importância da criatividade no processo de ensino aprendizagem. http://nippromove.hospedagemdesites.ws/anais_simposio/arquivos_up/documentos/artigos/bb04d efbd599055e0f72baf6c6027f01.pdf. Acesso: 18 dez. 2020.

TEXEIRA, J. P. Como não ser um Designer medíocre. https://medium.com/@joaopaulots/comon\%C3\%A3o-ser-um-designer-mediocre-513816dad64e. Acesso em: 14. dez. 2020.

\section{Reconhecimento}

Esta pesquisa, realizada no âmbito do Projeto Samsung-UFAM de Educação e Pesquisa (SUPER), de acordo com o artigo 48 do Decreto no 6.008/2006(SUFRAMA), foi financiada pela Samsung Electronics da Amazônia Ltda., nos termos da Lei Federal no 8.387/1991, por meio do convênio 001/2020, firmado com a Universidade Federal do Amazonas e a FAEPI, Brasil.

\section{Acknowledgement}

This research, carried out within the scope of the Samsung-UFAM Project for Education and Research (SUPER), according to Article 48 of Decree no 6.008/2006(SUFRAMA), was funded by Samsung Electronics of Amazonia Ltda., under the terms of Federal Law no 8.387/1991, through agreement $001 / 2020$, signed with Federal University of Amazonas and FAEPI, Brazil. 